\title{
Use of Proton Pump Inhibitors and the Risk of Hospitalization for Infectious Gastroenteritis
}

\author{
Yingxi Chen ${ }^{1}$, Bette Liu ${ }^{2}$, Kathryn Glass ${ }^{1}$, Wei Du ${ }^{1}$, Emily Banks ${ }^{1,3}$, Martyn Kirk ${ }^{1}$ * \\ 1 The Australian National University, Canberra, ACT, Australia, 2 University of New South Wales, Sydney, \\ NSW, Australia, 3 Sax Institute, Sydney, NSW, Australia \\ * martyn.kirk@anu.edu.au
}

\section{Abstract}

\section{Introduction}

To quantify the association between PPI use, type and dose and infectious gastroenteritis hospitalization in a population-based cohort of middle-aged and older adults.

\section{G openaccess}

Citation: Chen Y, Liu B, Glass K, Du W, Banks E, Kirk M (2016) Use of Proton Pump Inhibitors and the Risk of Hospitalization for Infectious Gastroenteritis. PLoS ONE 11(12): e0168618. doi:10.1371/journal.pone.0168618

Editor: John Green, University Hospital Llandough, UNITED KINGDOM

Received: September 1, 2016

\section{Methods}

Prospective study of 38,019 concession card holders followed up over 6 years in the Sax Institute's 45 and Up Study. Data from the baseline questionnaire were linked to prescription medication, hospitalization, notifiable disease, cancer registry and death datasets from 2006-2012. Associations between PPI use and gastroenteritis hospitalization were examined using Cox regressions with age as the underlying time variable.

\section{Results}

Accepted: December 2, 2016

Published: December 20, 2016

Copyright: $\odot 2016$ Chen et al. This is an open access article distributed under the terms of the Creative Commons Attribution License, which permits unrestricted use, distribution, and reproduction in any medium, provided the original author and source are credited.

Data Availability Statement: The 45 and Up Study is a cohort study of over 260,000 participants aged 45 years and above living in New South Wales (NSW), Australia. The study is managed by the Sax Institute, and it is an open research resource to help facilitate research on health, ageing and quality-of-life. The data set for the present study was created by linkage of 45 and Up Study baseline survey data to Australian Government and NSW state data sources with support of the Centre for Health Record Linkage (CHeReL) and permission from the custodians of each of the datasets under specific ethics approval managed by the Sax

Among 38,019 participants, the median age was 69.7 years, and $57.3 \%$ were women. Compared to non-users, current PPI users were more likely to be older, and have a higher BMI. During follow-up there were 1,982 incident gastroenteritis hospitalizations (crude rate: 12.9 per 1000 person-years, $95 \% \mathrm{Cl}$ : 12.3-13.5). PPI use was significantly associated with infectious gastroenteritis hospitalization (aHR 1.4, 95\% Cl: 1.2-1.5). Among current users, a dose-response relationship was observed between the average daily dose (DDD) dispensed per day and infectious gastroenteritis hospitalization $\left(P_{\text {trend }}<0.001\right)$. We also observed higher rates of infectious gastroenteritis hospitalization and greater PPI use among participants with a history of chronic bowel problems (aHR 2.2, 95\% Cl: 1.9-2.5). There was no difference in risk by type of $\mathrm{PPI}$. Recent use of $\mathrm{H}_{2}$ receptors was not associated with gastroenteritis hospitalization.

\section{Conclusion}

PPI use is associated with an increased risk of infectious gastroenteritis hospitalization. Clinicians should be aware of this risk when considering PPI therapy. 
Institute. The Sax Institute retains a copy of the resultant dataset. Interested researchers should contact the Sax Institute (45andUp. research@saxinstitute.org.au) and CHeReL (cherel. mail@moh.health.nsw.gov.au) for data access approval procedures.

Funding: YC received the 2014 Prime Minister's Australia Asia Postgraduate Scholarship from the Australian Government Department of Education and Training (3929_2014). BL is funded by an Australian National Health \& Medical Research Council Career Development Fellowship. The funders had no role in study design, data collection and analysis, decision to publish, or preparation of the manuscript

Competing Interests: The authors have declared that no competing interests exist.

\section{Introduction}

Proton pump inhibitors (PPIs), introduced in 1989, are the most potent gastric acid suppressants available [1]. They are widely used by both gastroenterologists and primary care physicians in the effective treatment of acid-related disorders. PPIs are one of the most commonly prescribed medications worldwide [2], although it has been suggested that $25-70 \%$ of patients taking PPIs lack appropriate indications [2]. In Australia, there are five PPIs listed on the Pharmaceutical Benefits Scheme (PBS) - a national government system that subsidizes the cost of medicines, most of which are dispensed by pharmacists. Omeprazole and lansoprazole were first introduced onto the PBS in 1994, followed by pantoprazole in 1995, rabeprazole in 2001 and esomeprazole in 2002. Since their introduction, PPI use in Australia has grown dramatically [3]. In the 2013-14 financial year, physicians issued over 19 million prescriptions for PPIs with the most commonly prescribed type of PPI costing the PBS over \$200 million [4].

Many patients take PPIs on a continuous or long-term basis [5]. Although this class of drug is considered safe and has been approved for long-term use [6], concerns have been raised regarding associated adverse effects [7]. Studies have reported that PPIs are associated with serious adverse events, including kidney diseases, hip fracture, community-acquired pneumonia, and Clostridium difficile infection [8-11]. PPIs irreversibly inactivate the gastric $\mathrm{H}^{+} / \mathrm{K}^{+}$ATPase pump and cause a profound inhibition of gastric acid secretion [12, 13]. Significant hypochlorhydria, particularly among the elderly population who may have decreased clearance of PPIs, could result in bacterial overgrowth [14] and potentially increase susceptibility to infection. PPI use has also been shown to reduce gut commensal load and microbial density [15].

Although PPIs can potentially impair gastrointestinal host defenses, the association between PPI use and enteric infections has only recently been explored systematically [16, 17]. Observational studies have found increased risks of Campylobacter, Salmonella and C. difficile infection $[9,18]$. However, the effects of different types and doses of PPIs remain unknown. Additionally, to our knowledge, no population-based studies have evaluated the effect of different PPI dosage and infectious gastroenteritis hospitalization among patients with chronic bowel problems. Given that older adults constitute the majority of PPI users [3, 19], the aim of this study was to investigate the association between PPI use and hospitalization for infectious gastroenteritis, considering both dose and type of PPIs, in a large prospective study of adults aged 45 years and older with and without a history of chronic bowel problems.

\section{Methods}

\section{Data sources and study population}

The Sax Institute's 45 and Up Study is an Australian cohort of 267,153 men and women aged 45 years and over from New South Wales (NSW), the most populous state in Australia. The 45 and Up Study cohort were randomly selected from the Medicare Australia (now the Department of Human Services) enrolment database. Baseline questionnaires were distributed from 1 January 2006 to 31 December 2008. Participants joined the study by completing the baseline questionnaire and giving consent for follow-up through repeated data collection and linkage of their data to multiple population health databases. Baseline questionnaire data include information on socio-demographics, general health and behavior. The study is described in detail elsewhere [20], and questionnaires can be accessed at http://www.45andup.org.au.

For this report we linked individual participant baseline data to prescription medication, hospitalization, notifiable disease, cancer registrations and death datasets. Specifically, the 45 and Up Study baseline questionnaire data were linked to medication data from the PBS 
records to obtain medication use at baseline and during follow-up. Questionnaire data were linked to hospitalization data from the NSW Admitted Patient Data Collection (APDC) to identify cases of infectious gastroenteritis and to capture participants with previous hospitalizations. In order to identify cases of Salmonella infection, which is a notifiable disease in NSW, baseline data were linked to the Notifiable Conditions Information Management System (NCIMS). Data were then linked to death data to ascertain fact and date of death for censoring purposes. Baseline data were also retrospectively linked to cancer registry data from the NSW Central Cancer Registry (CCR) to identify participants who had a cancer diagnosis before recruitment. The NSW Centre for Health Record Linkage performed the data linkage independent of the study investigators and report false positive and false negative linkages of $<0.5 \%$ and $<0.1 \%$, respectively [21].

The PBS dataset is an administrative dataset documenting information about subsided dispensed prescription drugs including PPIs for the Australian population [22]. For medicines listed on the PBS, consumers contribute a copayment towards the cost, and the Australian Government pays the remainder. People with a concession card pay a smaller copayment (AUD 6 in 2014) than the general population. Concession card holders are people with a Pensioner Concession Card, a Commonwealth Seniors Health Card or a Health Care Card. The PBS captured all medicines dispensed to concession card holders in the time period covered by these analyses.

The NSW APDC dataset is a complete census of all hospital admissions in NSW. The principal diagnosis for each admission, and up to 54 additional diagnoses contributing to the admission were coded using the International Classification of Diseases, $10^{\text {th }}$ revision, Australian Modification (ICD-10-AM) [23]. The NCIMS database contains a record of Salmonella infections in NSW, including the estimated onset date and the type of laboratory specimen used for confirmation. The NSW CCR is a population-based registry that records all new diagnoses of cancer in NSW residents and all deaths from cancer.

\section{Measurements}

Case definition. The primary outcome of interest was hospitalization with infectious gastroenteritis, which was defined as a participant with an index linked hospitalization record where the principal or a secondary diagnosis was coded with an ICD-10-AM code for intestinal infectious diseases (A00-A09) following study recruitment.

Secondary outcomes included Salmonella-, Campylobacter- and C. difficile infection. A case of Salmonella infection was defined as a participant who had a linked notification record of non-typhoidal Salmonella infection during follow up. A case of Campylobacter-, or C. difficile infection was defined as a participant who had a linked hospitalization record with diagnosis of Campylobacter enteritis (ICD-10-AM code A04.5), or C. difficile colitis (A04.7) during follow up, respectively.

Definition of PPI use. PPI use was identified using linked records on dispensing from the PBS dataset with Anatomical Therapeutic Chemical (ATC) classification codes beginning with A02BC, proton pump inhibitors (World Health Organization Collaborating Centre for Drug Statistics Methodology, 2013) [24]. Study participants were categorized as current PPI users, former users and non-users. Current users were defined as those who had at least one PPI dispensing record within the 3 months prior to recruitment. Former users were defined as participants who had at least one PPI dispensing record in a period of 3-12 months prior to recruitment. Non-users were defined as participants who were not dispensed any PPIs over the period prior to recruitment that we had PBS records for, or who had a PPI dispensed $\geq 12$ months prior to recruitment. 
Current users were further categorized by type of PPI and dose. Types of PPIs used included omeprazole (ATC codes: A02BC01), pantoprazole (A02BC02), lansoprazole (A02BC03), rabeprazole (A02BC04), esomeprazole (A02BC05) or more than one type. Dose was described as the average number of dispensed DDD per day during the 3 months prior to recruitment [25]. DDD is a World Health Organization classification system which is defined as 'the assumed average maintenance dose per day for a drug used for its main indication in adults' [26]. To obtain the average number of dispensed DDD per day, we firstly calculated the total number of dispensed DDD for each PPI, which was calculated as the strength (mg) of the dispensed PPI multiplied by the pack size and the number of dispensed packs, and then divided by the DDD of that PPI. This dispensed DDD was then summed for each participant and divided by the duration of use (3 months) to obtain the average dispensed DDD per day during the 3 months prior to the recruitment.

Definition of covariates. Socio-demographic factors and health status characteristics obtained from the baseline questionnaire included: age (grouped as 45-54, 55-64, 65-74 or $\geq 75$ years), sex, body mass index (BMI: $<18.5,18.5-24.9,25-29.9$ or $\geq 30 \mathrm{~kg} / \mathrm{m}^{2}$ ), self-rated health (excellent, good, fair or poor), smoking (current, past or never) and alcohol intake (none, 1-2 alcohol drinks per day or $>2$ alcohol drinks per day). Region of residence was obtained from Medicare Australia using address at time of recruitment, grouped as cities, inner regional or outer regional/remote based on the Accessibility/Remoteness Index of Australia [27].

History of cancer diagnosis, excluding non-melanoma skin cancer, in the 5 years prior to recruitment (yes, no) was ascertained by linkage to the CCR. History of chronic bowel problems (yes, no), was ascertained by linkage to an APDC record with an ICD-10-AM diagnosis code of K50 to K52 (non-infective enteritis and colitis) and K58 (irritable bowel syndrome) in any of the 55 diagnostic fields in the 6 years prior to recruitment. Recent $\mathrm{H}_{2}$ receptor antagonist and antibiotic use were defined based on the PBS dispensing records (ATC codes: A02BA01, A02BA02, A02BA03, A02BA04 for $\mathrm{H}_{2}$ receptors and J01 for antibiotics) in the 3 months before recruitment.

\section{Statistical methods}

In this study, complete records of dispensed PPIs were only available for people with a valid healthcare concession-card [25]. Therefore, analyses were restricted to 45 and Up Study participants who were concession-card holders. Additionally, participants were excluded from the analyses if they had missing data on date of entry into the study, or missing PBS data on dispensing. Follow-up was calculated from the date of recruitment to the index date of admission for infectious gastroenteritis, death, or the last date for which database records were available (30 June 2012), whichever came first. Rates of infectious gastroenteritis hospitalizations since baseline and 95\% confidence intervals (CIs) were calculated for PPI current users, former users and non-users at baseline.

Characteristics of PPI current users, former users and non-users were firstly compared using chi-squared tests. For the main analysis to examine the risk of PPI use and infectious gastroenteritis, Kaplan-Meier analysis with the log-rank test was first used to determine the probability of hospitalization with infectious gastroenteritis for current users, former users and non-users. Cox proportional hazards regression with age as the underlying time variable was then used to estimate the hazard ratios (HRs) and 95\% confidence intervals (CIs). Regression models were initially adjusted only for age (as this was the underlying time variable) and sex, and then further adjusted for region of residence, self-rated health, BMI, cancer in previous 5 years, history of chronic bowel problems, recent $\mathrm{H}_{2}$ receptor antagonist use, and recent antibiotic use. Finally, smoking and alcohol intake were also added to the model. 
In current users, the risk of infectious gastroenteritis hospitalization was further evaluated according to type and dose of PPIs. To examine the potential impact of chronic bowel problems on the association between PPI use and infectious gastroenteritis, models were then stratified by history of chronic bowel problems. Similar analyses were performed for the secondary outcomes of Salmonella-, Campylobacter-, and C. difficile infection, respectively.

The proportionality assumption of the Cox regression models were verified by plotting the Schoenfeld residuals against the time variable in each model, with the time-dependent form of the model used where covariates displayed non-proportionality of hazards. No violations were detected for PPI use. Significant violation was observed for recent antibiotic use, and this covariate was included as a time-dependent form in the models.

Sensitivity analysis was conducted by restricting cases to only those with a principal hospital diagnosis of infectious gastroenteritis. To examine the effects of changes in PPI use over time a second sensitivity analysis was conducted by restricting the study population to participants who remained in the same PPI use category during follow-up. We then conducted a third sensitivity analysis using a time-dependent Cox model with time-varying PPI ever-use. All analyses were carried out using STATA 12.1.

\section{Ethics approval}

The conduct of the 45 and Up Study was approved by the University of New South Wales Human Research Ethics Committee. Ethics approval for this study was obtained from the NSW Population and Health Services Research Ethics Committee, and the Australian National University Human Research Ethics Committee. All participants provided written informed consent.

\section{Results}

After restricting participants to those with concessional-only PBS records during the study period $(\mathrm{n}=38,074)$, and excluding those who had missing data on date of entry into the study ( $n=10)$, or missing PBS data on dispensing $(n=45)$, there were 38,019 participants, who were followed from baseline for a median of 3.9 years, yielding a total of 153,997 person-years of follow-up. The median age of study participants at recruitment was 69.7 years (interquartile range: $63.3-77.4$ ), and $57.3 \%$ were women.

Table 1 summarizes the characteristics of the study population. Overall, $52.1 \%(n=19,787)$ of participants had been dispensed at least one PPI in the 3 months prior to recruitment (categorized as PPI current users), $38.8 \%(\mathrm{n}=14,762)$ were defined as non-users, of which $18.8 \%$ $(\mathrm{n}=2,771)$ had a record of PPI use $\geq 12$ months before recruitment. PPI current users were more likely to be older and have a higher BMI compared to non-users. Participants taking $\mathrm{H}_{2}$ receptor antagonists had similar characteristics to participants taking PPIs (Table 1).

Among users, esomeprazole was the most frequently dispensed PPI ( $n=5,950 ; 30.1 \%)$, followed by omeprazole $(n=4,983 ; 25.2 \%)$ and pantoprazole $(n=4,235 ; 21.4 \%)$. Most users had used only one type of PPI $(\mathrm{n}=19,096 ; 96.1 \%)$.

There were 1,982 cases of incident infectious gastroenteritis hospitalization during followup. The crude incidence of gastroenteritis hospitalization in the cohort was 12.9 per 1,000 person years (95\% CI, 12.3-13.5). Compared to non-users, the adjusted relative risk of hospitalization was significantly higher in current PPI users (aHR 1.4, 95\% CI: 1.2-1.5) and former users (aHR 1.2, 95\% CI: 1.1-1.5) (Fig 1). Recent use of prescribed $\mathrm{H}_{2}$ receptors was not associated with hospitalization for infectious gastroenteritis (aHR 0.9, 95\% CI: 0.7-1.1). Participants with a history of cancer or chronic bowel problems were more likely to be hospitalized with infectious gastroenteritis (aHR 1.5, 95\% CI: 1.3-1.7; and 2.2, 95\% CI: 1.9-2.5, respectively). 
Table 1. Baseline characteristics of the study population, the 45 and Up Study, according to use of Proton Pump Inhibitors (PPI) and $\mathrm{H}_{2}$ receptor antagonists.

\begin{tabular}{|c|c|c|c|c|c|}
\hline Characteristics & $\begin{array}{l}\text { PPI non-users } \\
(\mathrm{n}=14,762)(\%)\end{array}$ & $\begin{array}{l}\text { PPI former users } \\
(n=3,470)(\%)\end{array}$ & $\begin{array}{l}\text { PPI current users } \\
(n=19,787)(\%)\end{array}$ & $\begin{array}{l}H_{2} \text { receptor users } \\
(n=1,951)(\%)\end{array}$ & $\begin{array}{l}P \text { - } \\
\text { value* }\end{array}$ \\
\hline Age (years) & & & & & $P<.001$ \\
\hline $45-54$ & $1,564(10.6)$ & $366(10.6)$ & $1,376(6.9)$ & $152(7.8)$ & \\
\hline $55-64$ & 3,440 (23.3) & $728(21.0)$ & $4,102(20.8)$ & $384(19.6)$ & \\
\hline $65-74$ & $5,503(37.3)$ & $1,354(39.0)$ & $7,517(38.0)$ & $729(37.4)$ & \\
\hline$\geq 75$ & $4,255(28.8)$ & $1,022(29.4)$ & 6,792 (34.3) & $686(35.2)$ & \\
\hline Female sex & $8,336(56.5)$ & $2,043(58.9)$ & $11,408(57.6)$ & $1,136(58.2)$ & $P=.3$ \\
\hline Region of residence & & & & & $P=.03$ \\
\hline Cities & $5,898(39.9)$ & $1,488(42.8)$ & 7,898 (39.9) & $881(45.1)$ & \\
\hline Inner regional & $5,467(37.1)$ & $1,245(35.9)$ & 7,568 (38.3) & $646(33.1)$ & \\
\hline Outer regional/remote & $3,397(23.0)$ & $737(21.3)$ & 4,321 (21.8) & $424(21.7)$ & \\
\hline $\begin{array}{l}\text { History of chronic bowel } \\
\text { problems }\end{array}$ & $692(4.7)$ & $249(7.2)$ & $1,752(8.9)$ & $158(8.1)$ & $P<.001$ \\
\hline Self-rated health & & & & & $P<.001$ \\
\hline Excellent & 4,919 (33.3) & $1,053(30.4)$ & $4,670(23.6)$ & $422(21.6)$ & \\
\hline Good & $5,484(37.2)$ & $1,258(36.3)$ & 7,569 (38.3) & $698(35.7)$ & \\
\hline Fair & $2,961(20.1)$ & $765(22.1)$ & $5,108(25.8)$ & $531(27.2)$ & \\
\hline Poor & $656(4.4)$ & $192(5.5)$ & $1,436(7.3)$ & $177(9.1)$ & \\
\hline Cancer in previous 5 years & $1,184(8.0)$ & $299(8.6)$ & $1,760(8.9)$ & $155(7.9)$ & $P=.03$ \\
\hline BMI $\left(\mathrm{kg} / \mathrm{m}^{2}\right)$ & & & & & $P<.001$ \\
\hline$<18.5$ & $233(1.7)$ & $63(1.9)$ & $288(1.6)$ & $25(1.4)$ & \\
\hline $18.5-24.9$ & $4,682(34.5)$ & $1,127(35.5)$ & $5,252(28.9)$ & $601(33.5)$ & \\
\hline $25-29.9$ & $5,125(37.7)$ & $1,164(36.7)$ & 6,999 (38.6) & $633(35.3)$ & \\
\hline$>30$ & $3,550(26.1)$ & $818(25.9)$ & $5,576(30.8)$ & $535(29.8)$ & \\
\hline Smoking & & & & & $P<.001$ \\
\hline Never & $7,610(51.9)$ & $1,829(53.0)$ & $10,195(51.8)$ & $1,021(52.9)$ & \\
\hline Current & $1,457(9.9)$ & $311(9.1)$ & $1,375(7.0)$ & $158(8.2)$ & \\
\hline Past & $5,599(38.2)$ & 1,308 (37.9) & $8,079(41.2)$ & $751(38.9)$ & \\
\hline Alcohol intake & & & & & $P<.001$ \\
\hline None & $6,349(43.0)$ & $1,534(44.2)$ & $9,053(45.7)$ & $955(48.9)$ & \\
\hline$\leq 2$ units/day & $6,211(42.1)$ & $1,431(41.2)$ & $7,951(40.2)$ & $718(36.8)$ & \\
\hline$>2$ units/day & $1,644(11.1)$ & $354(10.2)$ & $2,104(10.6)$ & $186(9.5)$ & \\
\hline
\end{tabular}

$P$-value*: Chi-squared test for PPI category. Missing: self-rated health = 1,948 (5.1\%); BMI = 3,142 (8.2\%); smoking = $256(0.6 \%)$; alcohol intake = 1,388 $(3.6 \%)$

doi:10.1371/journal.pone.0168618.t001

Among current users, a dose-response relationship was observed between the average number of DDD dispensed per day and risk of infectious gastroenteritis hospitalization $\left(P_{\text {trend }}<0.001\right)$, with a $60 \%$ increase in risk among those dispensed $>1$ DDD/day versus non-use (aHR 1.6, 95\% CI: 1.3-1.8). The risk did not differ significantly by PPI type (Table 2). The dose response effect was consistent when analyses were restricted to participants with a history of chronic bowel problems; compared to non-users, aHRs of infectious gastroenteritis hospitalization were 1.2 (95\% CI: 0.8-1.9) in participants with a dose $\leq 0.5 \mathrm{DDD} /$ day, 1.7 (95\% CI: 1.2-2.2) with a dose of 0.51DDD/day, and 2.0 (95\% CI: $1.4-2.8)$ with a dose $>1 \mathrm{DDD} /$ day $\left(P_{\text {trend }}<0.001\right)$ (Table 2$)$.

The broad relationships between PPI use and the risk of specific types of infectious gastroenteritis-C. difficile, Salmonella and Campylobacter infection-did not differ materially from that observed for infectious gastroenteritis hospitalization overall. Risks were significantly 


\begin{tabular}{|c|c|c|c|c|c|}
\hline Characteristics & $\begin{array}{l}\text { Cases/ } \\
\text { person-years }\end{array}$ & $\begin{array}{l}\text { Incidence } \\
(\mathbf{9 5 \%} \mathrm{CI}) \\
(1,000 \text { person- } \\
\text { years })\end{array}$ & $\mathrm{HR}^{*}(95 \% \mathrm{CI})$ & $\mathrm{HR}^{* *}(95 \% \mathrm{CI})$ & $\mathrm{HR}^{* *}$ \\
\hline \multicolumn{6}{|l|}{ PPI user categories } \\
\hline Non-users & $584 / 61,893$ & $9.4(8.7-10.2)$ & 1.0 & 1.0 & $\dot{\phi}$ \\
\hline Former users & $168 / 13,491$ & $12.5(10.7-14.5)$ & $1.3(1.1-1.6)$ & $1.2(1.1-1.5)$ & 淐 \\
\hline Current users & $1,230 / 78,611$ & $15.6(14.8-16.5)$ & $1.6(1.4-1.7)$ & $1.4(1.2-1.5)$ & $\theta$ \\
\hline \multicolumn{6}{|c|}{$\mathrm{H}_{2}$ receptor antagonist use } \\
\hline No & $1,879 / 146,004$ & $12.8(12.3-13.4)$ & 1.0 & 1.0 & $i$ \\
\hline Yes & $106 / 7,992$ & $13.3(11.0-16.0)$ & $0.9(0.7-1.2)$ & $0.9(0.7-1.1)$ & छ \\
\hline \multicolumn{6}{|l|}{ Recent antibiotic use } \\
\hline No & $1,263 / 107,668$ & $11.7(11.1-12.4)$ & 1.0 & 1.0 & i \\
\hline Yes & $719 / 46,328$ & $15.5(14.4-16.7)$ & $1.1(1.0-1.1)$ & $1.0(1.0-1.1)$ & 19. \\
\hline \multicolumn{6}{|l|}{ Sex } \\
\hline Female & $1,184 / 88,838$ & $13.3(12.6-14.1)$ & 1.0 & 1.0 & i \\
\hline Male & $798 / 65,158$ & $12.2(11.4-13.1)$ & $0.9(0.8-0.9)$ & $0.9(0.8-0.9)$ & $\dot{\epsilon}$ \\
\hline \multicolumn{6}{|l|}{ Region of residence } \\
\hline Cities & $953 / 61,040$ & $15.6(14.7-16.6)$ & 1.0 & 1.0 & i \\
\hline Inner regional & $652 / 58,226$ & $11.2(10.4-12.1)$ & $0.8(0.7-0.9)$ & $0.8(0.7-0.9)$ & 日i \\
\hline Outer regional/remote & $377 / 34,730$ & $10.9(9.8-12.0)$ & $0.8(0.7-0.9)$ & $0.8(0.7-0.9)$ & 日 \\
\hline \multicolumn{6}{|c|}{ Cancer in previous 5 years ${ }^{\#}$} \\
\hline No & $1,755 / 142,353$ & $12.3(11.8-12.9)$ & 1.0 & 1.0 & i \\
\hline Yes & $227 / 11,643$ & $19.5(17.1-22.2)$ & $1.5(1.3-1.8)$ & $1.5(1.3-1.7)$ & 是 \\
\hline \multicolumn{6}{|c|}{ History of chronic bowel problems } \\
\hline No & $1,664 / 143,898$ & $11.6(11.0-12.1)$ & 1.0 & 1.0 & $\dot{\varphi}$ \\
\hline Yes & $318 / 10,098$ & $31.5(28.2-35.1)$ & $2.6(2.3-3.0)$ & $2.2(1.9-2.5)$ & \\
\hline
\end{tabular}

Fig 1. Crude incidence and hazard ratios of participants admitted to hospital with infectious gastroenteritis according to Proton Pump Inhibitor (PPI) user categories and other characteristics.

doi:10.1371/journal.pone.0168618.g001

elevated for C. difficile infection among PPI current users (aHR: 1.5, 95\% CI: 1.1-2.1). Compared to non-users, participants dispensed $>1$ DDD/day were $120 \%$ more likely to have $C$. difficile infection (aHR: 2.2, 95\% CI: 1.4-3.4), and 100\% more likely to have Salmonella infection

Table 2. Hazard ratios of participants hospitalized with infectious gastroenteritis among current Proton Pump Inhibitor (PPI) users compared to non-users according to dose and type of PPI.

\begin{tabular}{|c|c|c|c|c|c|c|c|c|}
\hline \multirow[t]{2}{*}{ Characteristics } & \multirow[t]{2}{*}{$\mathrm{HR}^{*}(95 \% \mathrm{Cl})$} & \multirow[t]{2}{*}{$P_{\text {trend }}$} & \multicolumn{3}{|c|}{$\begin{array}{l}\text { Participants with chronic bowel } \\
\text { problems }\end{array}$} & \multicolumn{3}{|c|}{$\begin{array}{l}\text { Participants without chronic bowel } \\
\text { problems }\end{array}$} \\
\hline & & & Rate $^{\#}$ & $\mathrm{HR}^{* *}(95 \% \mathrm{Cl})$ & $P_{\text {trend }}$ & Rate $^{\#}$ & $\mathrm{HR}^{* *}(95 \% \mathrm{Cl})$ & $P_{\text {trend }}$ \\
\hline Average daily dose (DDD) & & $<0.001$ & & & $<0.001$ & & & $<0.001$ \\
\hline Non-users & 1.0 & & 22.1 & 1.0 & & 9.4 & 1.0 & \\
\hline$\leq 0.5$ & $1.1(0.9-1.3)$ & & 25.2 & $1.2(0.8-1.9)$ & & 10.8 & $1.1(0.9-1.3)$ & \\
\hline $0.5-1$ & $1.4(1.3-1.6)$ & & 37.5 & $1.7(1.2-2.2)$ & & 14.3 & $1.4(1.3-1.6)$ & \\
\hline$>1$ & $1.6(1.3-1.8)$ & & 45.1 & $2.0(1.4-2.8)$ & & 15.9 & $1.5(1.3-1.8)$ & \\
\hline Type of PPI & & 0.2 & & & 0.3 & & & 0.4 \\
\hline Omeprazole & 1.0 & & 36.7 & 1.0 & & 14.9 & 1.0 & \\
\hline Pantoprazole & $0.9(0.8-1.1)$ & & 38.8 & $1.1(0.7-1.6)$ & & 12.7 & $0.9(0.7-1.1)$ & \\
\hline Lansoprazole & $0.9(0.6-1.2)$ & & 21.6 & $0.7(0.3-1.7)$ & & 12.7 & $0.9(0.6-1.2)$ & \\
\hline Rabeprazole & $1.1(0.9-1.3)$ & & 44.8 & $1.3(0.8-2.0)$ & & 14.4 & $1.1(0.8-1.3)$ & \\
\hline Esomeprazole & $0.9(0.8-1.1)$ & & 33.1 & $0.9(0.6-1.4)$ & & 13.0 & $1.0(0.8-1.1)$ & \\
\hline
\end{tabular}

Rate ${ }^{\#} / 1,000$ person-years. $\mathrm{HR}^{*}$ Adjusted for age, sex, region of residence, self-rated health, BMI, cancer in previous 5 years, history of chronic bowel problems, $\mathrm{H}_{2}$ receptor antagonist use, recent antibiotic use, smoking and alcohol consumption. $\mathrm{HR}^{* *}$ Adjusted for age, sex, region of residence, self-rated health, $\mathrm{BMI}$, cancer in previous 5 years, recent $\mathrm{H}_{2}$ receptor antagonist use, recent antibiotic use, smoking and alcohol consumption.

doi:10.1371/journal.pone.0168618.t002 
Table 3. Proton Pump Inhibitor (PPI) use and the risk of Salmonella-, Campylobacter-, and Clostridium difficile-infection.

\begin{tabular}{|c|c|c|c|}
\hline \multirow[t]{2}{*}{ Characteristics } & $\begin{array}{l}\text { Salmonella infection } \\
(\mathrm{n}=84)\end{array}$ & $\begin{array}{l}\text { Campylobacter infection } \\
(\mathrm{n}=71)\end{array}$ & $\begin{array}{l}\text { C. difficile infection } \\
(\mathrm{n}=147)\end{array}$ \\
\hline & No. of events & No. of events & No. of events \\
\hline PPI Non-users & 30 & 21 & 43 \\
\hline PPI former users & 3 & 5 & 7 \\
\hline PPI current users & 51 & 45 & 97 \\
\hline $\begin{array}{l}\text { Association between medication use and } \\
\text { infections }\end{array}$ & $\mathrm{HR}^{*}(95 \% \mathrm{Cl})$ & $\mathrm{HR}^{*}(95 \% \mathrm{Cl})$ & $\mathrm{HR}^{* *}(95 \% \mathrm{Cl})$ \\
\hline \multicolumn{4}{|l|}{ PPI use } \\
\hline Non-users & 1.0 & 1.0 & 1.0 \\
\hline Former users & $0.5(0.2-1.6)$ & $1.1(0.4-2.9)$ & $0.7(0.3-1.6)$ \\
\hline Current users & $1.2(0.7-1.8)$ & $1.6(1.0-2.7)$ & $1.5(1.1-2.1)$ \\
\hline \multicolumn{4}{|l|}{$\mathrm{H}_{2}$ receptor antagonist use } \\
\hline No & 1.0 & 1.0 & 1.0 \\
\hline Yes & $1.1(0.3-3.3)$ & $2.3(0.9-5.9)$ & $0.6(0.2-1.7)$ \\
\hline \multicolumn{4}{|l|}{ Antibiotic use } \\
\hline No & 1.0 & 1.0 & 1.0 \\
\hline Yes & $1.4(0.9-2.3)$ & $1.0(0.6-1.6)$ & $1.1(0.8-1.5)$ \\
\hline \multicolumn{4}{|l|}{ Average daily dose (DDD) } \\
\hline Non-users & 1.0 & 1.0 & 1.0 \\
\hline Current users: $\leq 0.5$ & $0.8(0.3-1.9)$ & $1.4(0.6-3.1)$ & $1.2(0.6-2.1)$ \\
\hline Current users: $0.5-1$ & $1.3(0.8-2.1)$ & $1.8(1.1-3.0)$ & $1.3(0.9-2.0)$ \\
\hline Current users: >1 & $2.0(1.1-3.8)$ & $1.1(0.4-2.7)$ & $2.2(1.4-3.4)$ \\
\hline
\end{tabular}

$\mathrm{HR}^{*}$ Adjusted for age, sex, region of residence, self-rated health, recent $\mathrm{H}_{2}$ receptor antagonist use, recent antibiotic use, cancer in previous 5 years, history of chronic bowel problems, and alcohol consumption. BMI and smoking status were not included in the model due to missing values in certain categories. $\mathrm{HR}^{* *}$ Adjusted for age, sex, region of residence, self-rated health, $\mathrm{BMI}$, recent $\mathrm{H}_{2}$ receptor antagonist use, recent antibiotic use, cancer in previous 5 years, history of chronic bowel problems, smoking and alcohol consumption.

doi:10.1371/journal.pone.0168618.t003

(aHR: 2.0, 95\% CI: 1.1-3.8). While not statistically significant in all cases, there was a pattern of increased risk of these outcomes with increasing PPI dose, and this pattern was not generally observed for $\mathrm{H}_{2}$ receptor antagonists (Table 3).

\section{Sensitivity Analyses}

The results remained similar when restricting cases to only those with a principal hospital diagnosis of infectious gastroenteritis; compared to non-users, aHRs were 1.7 (95\% CI: 1.4-1.9) for current users and 1.5 (95\% CI: 1.2-2.0) for former users. A significant dose-response relationship was also observed; compared to non-users, aHRs were 1.1 (95\% CI: 0.9-1.4), 1.4 (95\% CI: $1.2-1.7)$ and 2.1 (95\% CI: $1.8-2.5)$ in participants with a dose $\leq 0.5,0.5-1$ and $>1 \mathrm{DDD} /$ day, respectively $\left(P_{\text {trend }}<0.001\right)$. In the second sensitivity analysis with PPI use as a time-varying covariate, PPI use was also associated with infectious gastroenteritis hospitalization (aHR: 1.9, 95\% CI: 1.6-2.1). Associations remained similar when further restricting the study population to participants who did not change PPI use category during follow-up. A similar dose-response relationship was retained in this analysis $\left(P_{\text {trend }}<0.001\right)$.

\section{Discussion}

In this study, we found a significantly increased risk of infectious gastroenteritis hospitalization associated with PPI use, and a significant dose-response relationship among current 
users. This risk was specific to PPI users, as use of $\mathrm{H}_{2}$ receptor antagonists, which are used for the same indication as PPIs, was not associated with hospitalization due to infectious gastroenteritis. This study confirms that the risk of infectious gastroenteritis hospitalization is elevated in people who have used PPIs, and also provides new and reliable information about the effects of different types of PPIs and dosages.

We found that former and current PPI users had significantly increased risks of infectious gastroenteritis hospitalization compared to those never using or using PPIs $\geq 12$ months prior to baseline. Previous studies have reported current PPI therapy as a significant risk factor for bacterial gastroenteritis $[18,28]$. Howell et al reported increasing rates of nosocomial $C$. difficile infection with increasing level of PPI therapy [29]. In this study, we observed a significant dose-response relationship between PPI exposure and all-cause infectious gastroenteritis hospitalization, which has not been demonstrated previously. This dose-response relationship, and the fact that it is specific to PPIs and was not seen in users of $\mathrm{H}_{2}$ receptor antagonists, supports a causal association. In this study, we found a small elevation in risk of gastroenteritis hospitalization among former users, which has not been investigated previously; it may be due to long-term effects of PPI use, but requires confirmation.

The reason for the association between PPI use and infectious gastroenteritis is not known definitively, although colonization and proliferation of pathogens secondary to acid suppressive treatment is one potential explanation. Gastric acid plays an important role in preventing human gastrointestinal infections [30] and an acidic environment in the upper gastrointestinal tract constitutes one of the major non-specific defenses to protect against ingested microorganisms [31]. Acid suppression induced by PPIs also affects gastrointestinal motility and can indirectly alter gut microbiota [32]. In patients with functional bowel disorders, such as irritable bowel syndrome, such changes could be more pronounced $[33,34]$. Our study found that PPI use resulted in elevated risk of infectious gastroenteritis hospitalization in people with and without a history of chronic bowel problems. We also observed higher rates of infectious gastroenteritis hospitalization and greater PPI use among participants with a history of chronic bowel problems, indicating greater absolute risks of PPI-attributable hospitalization in this group. This suggests that the necessity for PPI use may need to be evaluated more carefully in this group of patients.

Previous studies have reported associations between PPI use and enteric infections, such as Campylobacter, Salmonella [18] and C. difficile infection [35]. We found a broad association between PPI use and Campylobacter-, Salmonella- and C. difficile infection. While the association was not statistically significant in all cases, which could be due to smaller number of events, there was a pattern of increased risk of infections in PPI users and potential doseresponse relationships. In addition, our prior work using the full 45 and Up Study dataset showed a significant risk of Salmonella infection among people who self-reported PPI use at baseline (aHR 1.87, 95\%CI 1.43-2.40) [36]. Our findings regarding C. difficile infection were consistent with published data. A recent systematic review of 39 studies showed PPI users at higher risk of $C$. difficile infection compared to non-users (odds ratio: 1.74, 95\%CI 1.47-2.85) [9]. Based on latest evidence, the FDA have published safety alerts warning of the association between C. difficile diarrhea and PPIs [37]. In Europe, PPI use for more than 8 weeks at the maximal dose without clear indication has been listed on the European list (EU [7)-PIM list) of potentially inappropriate medications for older people due to the association between PPI use and C. difficile infection [38].

To ensure that the study focused on the likely causal effect of PPI use on infectious gastroenteritis hospitalization, comorbidity status was controlled through adjustments of cancer history, general health and BMI. Participants with digestive disorders may be more likely to be prescribed acid suppressive medications. These patients also may be more likely to experience 
infectious gastroenteritis and be hospitalized. It was not possible to account for all possible digestive disorders, although we identified participants with chronic bowel problems at baseline and adjusted for them in the regression models. We also stratified results by the status of chronic bowel problems. To examine the effect of confounding by indication of acid suppressive therapy, we considered recent $\mathrm{H}_{2}$ receptor antagonist use in the analysis. Similar to PPIs, $\mathrm{H}_{2}$ antagonists are a class of acid suppressants used to treat acid-related disorders such as peptic ulcers. We did not observe any increased risk of infection among $\mathrm{H}_{2}$ receptor antagonist users, indicating that confounding by indication was unlikely to be a major source of bias in this study.

The large number of cases in the study enhanced the precision of the estimates, and allowed adequate assessment of the effects of potential confounders. However, we were only able to classify based on medication usage from dispensing data rather than directly observed therapy, meaning we were unable to confirm actual PPI use in this study. Misclassification relating to non-use among those with records of having been dispensed PPIs would tend to lead to an overestimation of the potential risk of PPIs. However, this bias would be unlikely to affect the assessment of dose, as it is less likely that patients with multiple dispensing records of PPIs did not take the medication. In addition, a recent systematic review suggested that the majority of patients with GERD are relatively adherent to PPIs, and adherence increases with severe symptoms [39]. Secondly, as with most observational studies, residual confounding by unmeasured factors is a potential concern. In this study, we controlled for several important confounders, although we were unable to assess other factors, such as use of over-the-counter antacids. During the study period, low-dose PPIs were available from pharmacies without a prescription in Australia, which could lead to misclassification of PPI exposure. Thirdly, inpatient hospitalization data can be subject to misclassification. However, sensitivity analysis restricting cases only to principal diagnosis of infectious gastroenteritis showed similar results to the main findings. Finally, the study population was restricted to concession-card-holders. Therefore, participants were likely to be older, with lower socio-economic status, when compared to the broader cohort, although risk factor estimates are considered broadly generalizable from within-cohort comparisons [40].

In summary, PPI use is associated with an increased risk of infectious gastroenteritis hospitalization in the 45 and Up Study participants, with higher risks with increasing doses. Given the widespread use of PPIs, particularly among the elderly, clinicians should be aware of this risk when considering PPI therapy, and use the lowest effective dose for patients with appropriate indications. For patients with chronic bowel problems, it may be worth considering an alternative dosage or switching to $\mathrm{H}_{2}$ receptor antagonists.

\section{Acknowledgments}

This research was completed using data collected through the 45 and Up Study (www. saxinstitute.org.au). The Commonwealth Department of Human Services supplied the PBS data.

The 45 and Up Study is managed by the Sax Institute in collaboration with major partner Cancer Council NSW; and partners: the National Heart Foundation of Australia (NSW Division); NSW Ministry of Health; NSW Government Family \& Community Services-Carers, Ageing and Disability Inclusion; and the Australian Red Cross Blood Service. We thank the many thousands of people participating in the 45 and Up Study.

\section{Author Contributions}

Conceptualization: YC BL KG MK. 
Data curation: YC BL.

Formal analysis: YC.

Funding acquisition: BL.

Investigation: YC BL KG WD.

Methodology: YC BL KG WD.

Project administration: YC BL MK.

Resources: BL EB.

Software: YC.

Supervision: BL MK.

Validation: YC BL KG MK.

Visualization: YC BL MK.

Writing - original draft: YC.

Writing - review \& editing: YC BL KG WD EB MK.

\section{References}

1. Wolfe MM, Sachs G. Acid suppression: optimizing therapy for gastroduodenal ulcer healing, gastroesophageal reflux disease, and stress-related erosive syndrome. Gastroenterol. 2000; 118(2 Suppl 1): S9-31.

2. Forgacs I, Loganayagam A. Overprescribing proton pump inhibitors. BMJ. 2008; 336(7634):2-3. doi: 10.1136/bmj.39406.449456.BE PMID: 18174564

3. Hollingworth S, Duncan EL, Martin JH. Marked increase in proton pump inhibitors use in Australia. Pharmacoepidemiol Drug Saf. 2010; 19:1019-24. doi: 10.1002/pds.1969 PMID: 20623646

4. The Pharmaceutical Benefits Scheme, PBS Statistics [Internet]. Australian Government Department of Health,. [cited 15 November 2015]. Available from: http://www.pbs.gov.au/info/browse/statistics\#ASM.

5. Jacobson BC, Ferris TG, Shea TL, Mahlis EM, Lee TH, Wang TC. Who is Using Chronic Acid Suppression Therapy and Why. Am J Gastroenterol. 2003; 98:51-8. doi: 10.1111/j.1572-0241.2003.07186.X PMID: 12526936

6. Garnett WR. Considerations for long-term use of proton-pump inhibitors. AJHP. 1998; 55:2268-79. PMID: 9825878

7. Schoenfeld AJ, Grady D. Adverse Effects Associated With Proton Pump Inhibitors. JAMA Intern Med. 2016; 176:172-174. doi: 10.1001/jamainternmed.2015.7927 PMID: 26751904

8. Yang YX, Lewis JD, Epstein S, Metz DC. Long-term proton pump inhibitor therapy and risk of hip fracture. JAMA. 2006; 296:2947-53. doi: 10.1001/jama.296.24.2947 PMID: 17190895

9. Kwok CS, Arthur AK, Anibueze CI, Singh S, Cavallazzi R, Loke YK. Risk of Clostridium difficile infection with acid suppressing drugs and antibiotics: meta-analysis. Am J Gastroenterol. 2012; 107:1011-9. doi: 10.1038/ajg.2012.108 PMID: 22525304

10. Filion KB, Chateau D, Targownik LE, Gershon A, Durand M, Tamim H et al. Proton pump inhibitors and the risk of hospitalisation for community-acquired pneumonia: replicated cohort studies with meta-analysis. Gut. 2014; 63:552-8. doi: 10.1136/gutjnl-2013-304738 PMID: 23856153

11. Lazarus $B$, Chen $Y$, Wilson FP, Sang $Y$, Chang AR, Coresh $J$ et al. Proton Pump Inhibitor Use and the Risk of Chronic Kidney Disease. JAMA Intern Med. 2016; 176.

12. Shin JM, Kim N. Pharmacokinetics and pharmacodynamics of the proton pump inhibitors. J neurogastroenterol Motil. 2013; 19:25. doi: 10.5056/jnm.2013.19.1.25 PMID: 23350044

13. Sharma BK, Walt RP, Pounder RE, Gomes MD, Wood EC, Logan LH. Optimal dose of oral omeprazole for maximal 24 hour decrease of intragastric acidity. Gut. 1984; 25:957-64. PMID: 6469081

14. Lombardo L, Foti M, Ruggia $O$, Chiecchio A. Increased incidence of small intestinal bacterial overgrowth during proton pump inhibitor therapy. Clin Gastroenterol Hepatol. 2010; 8:504-8. doi: 10.1016/j. cgh.2009.12.022 PMID: 20060064 
15. Jackson MA, Goodrich JK, Maxan ME, Freedberg DE, Abrams JA, Poole AC. Proton pump inhibitors alter the composition of the gut microbiota. Gut.

16. Martinsen TC, Bergh K, Waldum HL. Gastric juice: a barrier against infectious diseases. Basic Clin Pharmacol Toxicol. 2005; 96:94-102. doi: 10.1111/j.1742-7843.2005.pto960202.x PMID: 15679471

17. Dial MS. Proton pump inhibitor use and enteric infections. Am J Gastroenterol. 2009; 104:S10-S6. doi: 10.1038/ajg.2009.46 PMID: 19262540

18. Garcia Rodriguez LA, Ruigomez A, Panes J. Use of acid-suppressing drugs and the risk of bacterial gastroenteritis. Clin Gastroenterol Hepatol. 2007; 5:1418-23. doi: 10.1016/j.cgh.2007.09.010 PMID: 18054750

19. Ryder SD, O'Reilly S, Miller RJ, Ross J, Jacyna MR, Levi AJ. Long term acid suppressing treatment in general practice. BMJ. 1994; 308:827-30. PMID: 8167491

20. 45 and Up Study Collaborators, Banks E, Redman S, Jorm L, Armstrong B, Bauman A. Cohort profile: the 45 and Up Study. Int J Epidemiol. 2008; 37:941-7. doi: 10.1093/ije/dym184 PMID: 17881411

21. Centre for Health Record Linkage. Available from: www.cherel.org.au. Accessed Aug 2014.

22. Duckett SJ. Drug policy down under: Australia's pharmaceutical benefits scheme. Health Care Financing Review. 2003; 25:55-67.

23. National Centre for Classification in Health. Internationl statistical classification of diseases and related health problems, 10th revision, Australian Modification (ICD-10-AM). 5th edn. In: National Centre for Classification in Health: Sydney N, Australia, editor.: National Centre for Classification in Health: Sydney, NSW, Australia; 2006.

24. ATC/DDD index [Internet]. WHO Collaborating Centre for Drug Statistics Methodology. 2013. Available from: http://www.whocc.no/atc_ddd_index/?showdescription=yes\&code=A02BC.

25. Page E, Kemp-Casey A, Korda R, Banks E. Using Australian Pharmaceutical Benefits Scheme data for pharmacoepidemiological research: challenges and approaches. Public Health Research \& Practice. 2015; 25:e2541546.

26. Organization WH. World Health Organization Collaborating Centre for Drug Statistics Methodology. ATC index with DDDs. 2005.

27. Anon. ARIA and Accessibility 2014 [cited 201401 Oct]. Available from: https://www.adelaide.edu.au/ apmrc/research/projects/category/aria.html.

28. Hassing RJ, Verbon $\mathrm{A}$, de Visser $\mathrm{H}$, Hofman $\mathrm{A}$, Stricker $\mathrm{BH}$. Proton pump inhibitors and gastroenteritis. Eur J Epidemiol. 2016; 31:1057-63. doi: 10.1007/s10654-016-0136-8 PMID: 26960438

29. Howell MD, Novack V, Grgurich P, Soulliard D, Novack L, Pencina M. latrogenic gastric acid suppression and the risk of nosocomial Clostridium difficile infection. Arch Intern Med. 2010; 170:784-90. doi: 10.1001/archinternmed.2010.89 PMID: 20458086

30. Williams C, McColl KE. Review article: proton pump inhibitors and bacterial overgrowth. Aliment Pharmacol Ther. 2006; 23:3-10.

31. Howden C, Hunt R. Relationship between gastric secretion and infection. Gut. 1987; 28:96-107. PMID: 3546004

32. Vesper BJ, Jawdi A, Altman KW, Haines GK 3rd, Tao L, Radosevich JA. The effect of proton pump inhibitors on the human microbiota. Current drug metabolism. 2009; 10:84-9. PMID: 19149516

33. Compare D, Pica L, Rocco A, De Giorgi F, Cuomo R, Sarnelli G. Effects of long-term PPI treatment on producing bowel symptoms and SIBO. Eur J Clin Invest. 2011; 41:380-6. doi: 10.1111/j.1365-2362. 2010.02419.x PMID: 21128930

34. Simren M, Barbara G, Flint HJ, Spiegel BM, Spiller RC, Vanner S. Intestinal microbiota in functional bowel disorders: a Rome foundation report. Gut. 2013; 62:159-76. doi: 10.1136/gutjnl-2012-302167 PMID: 22730468

35. Cunningham R, Dale B, Undy B, Gaunt N. Proton pump inhibitors as a risk factor for Clostridium difficile diarrhoea. J Hosp Infect. 2003; 54:243-5. PMID: 12855243

36. Chen Y, Glass K, Liu B, Hope K, Kirk M. Salmonella Infection in Middle-Aged and Older Adults: Incidence and Risk Factors from the 45 and Up Study. Foodborne Pathog Dis. In press.

37. Proton Pump Inhibitors Information [Internet]. 2015 [cited February 02, 2016]. Available from: http:// www.fda.gov/drugs/drugSafety/InformationbyDrugClass/ucm213259.

38. Renom-Guiteras A, Meyer G, Thürmann PA. The EU (7)-PIM list: a list of potentially inappropriate medications for older people consented by experts from seven European countries. Eur J Clin Pharmacol. 2015:1-15.

39. Hungin APS, Hill C, Molloy-Bland M, Raghunath A. Systematic review: patterns of proton pump inhibitor use and adherence in gastroesophageal reflux disease. Clin Gastroenterol Hepatol. 2012; 10:10916. doi: 10.1016/j.cgh.2011.07.008 PMID: 21782770 
40. Mealing NM, Banks E, Jorm LR, Steel DG, Clements MS, Rogers KD. Investigation of relative risk estimates from studies of the same population with contrasting response rates and designs. BMC Med Res Methodol. 2010; 10:26. doi: 10.1186/1471-2288-10-26 PMID: 20356408 